\title{
"O Brasil é um país extremamente machista": entrevista com Luiz Ruffato
}

Por Christian Grünnagel ${ }^{1}$ e Doris Wieser ${ }^{2}$

\section{O que significa ser homem ou ser mulher para você?}

Eu acho que essa pergunta é complexa porque, se pensarmos em termos abstratos, ser homem ou ser mulher depende muito do lugar onde você vive. No país onde vivo, o Brasil, ser homem ou ser mulher não determina só uma questão de sexualidade, determina também a posição na sociedade. E o Brasil é um país extremamente machista. Só para terem uma ideia de como o Brasil é um país machista: eu tenho organizado diversas antologias temáticas, por exemplo sobre política, sobre as mulheres, sobre o racismo, sobre a questão da homossexualidade, e todas essas antologias foram adquiridas pelo governo num projeto de compras para bibliotecas públicas, exceto a que discute a questão da homossexualidade. Comprava a questão de mulheres, comprava a de política, mas a questão da homossexualidade, não. Mas veja bem: é feita uma consulta muito ampla, correta e transparente para avaliar os livros a serem adquiridos. Não estamos falando de um governo específico, não estamos falando de grupos. Portanto, estamos falando de um tabu mesmo. Não é questão de essa ou aquela pessoa não gostar do assunto, mesmo diante de uma ampla consulta, o tema não é aprovado.

Veja bem: não é uma antologia gay, é uma antologia sobre a questão da homossexualidade, e não foi adquirida. Isso já mostra bastante bem como nós, no Brasil, lidamos com a questão do gênero. O Brasil é o oitavo país com o maior número de assassinatos de mulheres no mundo. Na última década, nós, os brasileiros, matamos 45 mil

\footnotetext{
${ }^{1}$ Doutor em letras românicas e professor do Instituto de Filologia Românica da Universidade de Giessen, Giessen, Alemanha. E-mail: christian.gruennagel@ romanistik.uni-giessen.de

2 Doutora em literatura ibero-americana e professora do Instituto de Filologia Românica da Universidade de Göttingen, Göttingen, Alemanha. Atualmente bolsista de pós-doutorado da Fundação Alexander von Humboldt na Universidade de Lisboa. E-mail: doris.wieser@phil.unigoettingen.de
} 
mulheres. Mas veja bem: nós matamos 45 mil mulheres - e eu digo "nós" porque eu também sou brasileiro e detesto aquela história de "ah, os brasileiros". Esses números são números conhecidos, só que a violência doméstica, como ela está entre quatro paredes, ela não aparece, por isso esse número deve ser muitíssimo maior.

Quer dizer que o machismo tem ainda um papel muito importante na sociedade do Brasil atual. Em toda a sociedade ou há uma diferença entre as regiões ou as classes?

Nenhuma. Mata-se, e a violência doméstica na classe média alta é tão alta como na classe média baixa, com um detalhe muito interessante: na classe média baixa, quando um homem agride uma mulher, ela faz escândalo, chama, berra, grita e a gente acorda. Na classe média alta, não! Porque pega mal, porque é uma vergonha pública. Eu acho que dentro da classe média alta são muito mais hipócritas porque as mulheres são ofendidas e agredidas, mas vão muito menos às delegacias denunciar os homens, inclusive porque, muitas vezes, são casamentos que tem muito dinheiro envolvido, e portanto, a separação envolve muito mais coisas do que entre pobres, em que a separação se dá, digamos, apenas "entre corpos". A violência doméstica na classe média alta é tão grande quanto na classe baixa.

\section{Você vê também avanços na situação legal?}

Veja bem, é possível, mas não como regra, lei geral. Você tem que entrar com um processo na justiça e o juiz decide se dá o direito ou não. Eu sempre gosto de lembrar que nós, os brasileiros, somos hipócritas. Por exemplo, na avenida Paulista, onde se organiza a maior parada gay do mundo, é onde tem um dos maiores números de agressões a homossexuais no Brasil. Não há uma estatística segura, mas o número que vou informar é uma estimativa: são 200 homossexuais mortos por ano no Brasil só pelo fato de serem homossexuais. É um país muito hipócrita. E veja bem, quando eu digo isso, parece que estou atacando, mas não, eu estou simplesmente tentando mostrar como isso é um problema e como nós temos que nos esforçar para resolver esse problema.

Há uma socióloga australiana chamada Connell que propõe um modelo de vários "projetos" de masculinidade e fala deste fenómeno no plural: 
Masculinidades. ${ }^{3}$ No Brasil, há uma diferença entre a masculinidade da periferia e a masculinidade da classe média e alta?

Eu acredito que há tais diferenças, mas que são muito sutis. Eu sempre imaginei que a questão do machismo estivesse relacionada à questão da educação. Eu não mais acho isso, pois eu acreditava que à medida que você fosse se educando e adquirindo conhecimento, ia começar a perceber um pouco melhor o "diferente" - e com isso eu me refiro a homens, mulheres, ao diferente de você - com mais respeito, em tentativa de compreensão do outro, e pelo que vejo hoje no Brasil, isso não ocorre. Isso não tem a ver com educação, tem a ver com cultura, que são coisas diferentes. Então, você pode até ampliar sua educação, mas a cultura machista não muda, porque ela está impregnada na sociedade inteira. Um exemplo curioso: as mulheres no Brasil, quando fazer um seguro do carro, pagam menos do que os homens, uma vez que, estatisticamente, elas são mais prudentes no trânsito. No entanto, todas as vezes que um homem está no trânsito e há algum problema ele diz "É uma mulher", embora estatisticamente isso não seja verdade. Então, eu antigamente pensava sinceramente que se tratava de uma questão de educação, e hoje eu tendo a não achar mais isso; é uma questão cultural. Nós somos machistas, nós temos uma dificuldade enorme em lidar com essa mulher nova, que ocupa um lugar no mercado, que tem independência, que é uma mulher intelectual. Eu acho que isso é muito claro para mim, que nós não sabemos lidar com essa nova mulher.

Agora uma pergunta mais literária: nos estudos do gênero na atualidade há um assunto que se discute muito, que é se a feminilidade e a masculinidade no fundo são fenômenos naturais, do corpo. O que você, particularmente, acha sobre isso?

É um tema complicado. Eu não saberia responder isso com segurança. O que eu acho, e o que é evidente, é que o fato de você ocupar um corpo, seja ele masculino ou feminino, deve significar alguma coisa. Mas ao mesmo tempo, a cultura, o homem e a mulher dentro da cultura, isso também é importante para a pessoa se posicionar no mundo. Talvez a resposta seja uma convergência das duas coisas, ou seja, é você admitir que o fato de nascer homem ou mulher determina um pouco seu lugar

\footnotetext{
${ }^{3}$ Para mais detalhes sobre o enfoque teórico de Connell, veja-se o texto introdutório deste dossiê.
} 
no mundo, mas ao mesmo tempo saber que isso se amplia ou se torna menor ou maior dependendo de como você estabelece relações na sociedade. Mas eu não estou muito convencido disso, é uma questão muito complexa e hoje eu me deteria a dizer isso, a pensar assim.

E para falarmos também sobre a literatura: sendo um escritor masculino, como você trabalha para criar uma personagem do sexo oposto? Você trabalha diferente para criar as personagens femininas que aparecem nos seus textos?

Sinceramente, quando vou escrever, eu me coloco no lugar do outro, tento criar uma alteridade, sendo um cachorro, uma criança, uma mulher, um homem, um velho, um índio, um negro, enfim. O que eu tento fazer é sair de mim e tentar vestir a pele do outro, e, nesse momento, quando eu faço isso, eu estou abrindo mão da minha subjetividade para exercer uma outra subjetividade. E isso independentemente do fato de isso ser uma tentativa; se se consegue ou não se consegue, não podemos saber, mas essa é minha estratégia: me despir de mim mesmo e me vestir do outro. Então para mim, não é uma mudança de visão de mim, é na verdade uma mudança de pele.

Já falando um pouco mais concretamente sobre sua obra, é bastante chamativo na sua literatura o uso de diferentes fontes tipográficas, de diferentes formatações de texto. É uma ideia realmente sua ou há algum modelo na literatura que te influenciou.

A literatura é sempre devedora do que veio antes. Então, não diria que é uma invenção minha, mas é claro que isso tem um objetivo, um significado. E o significado disso é o seguinte: quando eu comecei a pensar em escrever sobre esse universo sobre o qual eu escrevo, que é o universo da classe média baixa, eu me deparei com um problema muito grave do ponto de vista estético. O romance é uma forma de visão de mundo burguesa, e eu fiquei pensando como eu poderia escrever sobre a classe média baixa, sobre o proletariado, usando essa forma burguesa. Era uma contradição. Ai eu passei muitos anos sabendo do que eu queria escrever, mas sem saber como eu poderia escrever. Minha questão nunca foi "o que?", mas "como?", a forma é que para mim era fundamental. Quem me deu a solução para esse problema foi Machado de Assis. Ele me deu a seguinte associação: no livro Memórias póstumas 
de Brás Cubas ele faz um romance que, do ponto de vista formal, é revolucionário. Muitos críticos de Machado de Assis discutem a questão do conteúdo, mas não discutem a questão formal. E ele é um escritor muito bondoso: ele diz de onde vem, quem são os autores com quem ele dialoga. Então eu fui simplesmente procurar os autores com quem ele dialoga: Xavier de Maistre, Sterne, Almeida Garrett. Machado de Assis me deu os caminhos, então eu fiz o caminho contrário, eu fui buscar esses autores e então fiz o caminho de volta. E tal caminho de volta é muito interessante porque o Machado de Assis termina ainda no século XIX, e naquele mesmo caminho que ele abriu, vieram outros autores. Veio o tom da poesia da virada do século XIX para o século XX de vanguarda, veio o Joyce, o Faulkner; mais à frente, no Brasil, veio ainda o movimento modernista. Dessa forma, essa estratégia de narrativa não é uma coisa gratuita, não é uma coisa fortuita. Ela tem a ver exatamente com essa perspectiva de tentar elaborar uma forma que desse conta do conteúdo que eu queria discutir. Eles eram muitos cavalos era inicialmente para mim um mero exercício formal; eu vejo esse livro mais como uma instalação literária, um laboratório, do que como um romance em si. O que eu queria ali? Eu queria exatamente experimentar para encontrar a linguagem do Inferno provisório.

Você é um dos autores brasileiros com maior preocupação estilística na atualidade. Você vê também alguma conexão entre a sua obra e a de Marcelino Freire em nível formal e estilístico, porque para o Marcelino o "como?" é também tão importante quanto ou mais importante do que o "o que?"

Não sei. Eu entendo o caminho, mas acho que não há uma conexão, porque o que o Marcelino percebe de uma maneira muito boa é uma oralidade, quase uma tentativa de recuperar - artificialmente, porque a literatura é artificial - uma linguagem muito oral. É evidente que no meu caso também há essa questão da linguagem, mas eu tento recuperar uma, digamos, sofisticação narrativa, que para mim era importante muito mais em função de provar que é possível escrever sobre personagens e famílias pobres com uma linguagem e psicologia ricas, com poesia, do que uma linguagem pobre, com uma psicologia pobre, de rebaixamento. Não estou dizendo que o Marcelino faça isso, evidentemente que não. Estou dizendo que são estratégias de narrativas diferentes. 
As suas obras sempre se anunciam como romances, mas quando eu li Eles eram muitos cavalos eu me perguntei "Isto é um romance?". Qual é o seu conceito de romance?

$\mathrm{Eu}$ adoro falar sobre isso. Eu acho que os escritores hoje em dia escrevem os livros, mas não gostam de falar sobre os livros. Eu gosto de pensar sobre os livros, pois a partir da minha reflexão eu amplio - ou não - o meu repertório. Eu te responderia da seguinte maneira: eu acho que da mesma maneira que o capitalismo do século XIX era diferente do capitalismo do século XXI o romance também muda porque o romance é uma expressão literária do capitalismo. A estratégia de percepção para mim é a física. A física é a ciência da natureza e persegue uma explicação de como a natureza funciona. Ela faz isso propondo algumas teorias e elaborando instrumentos para a compreensão. Eu vejo a minha literatura também como uma tentativa de compreensão da natureza humana e ela também tenta criar instrumentos de compreensão. É por isso que hoje a física é quântica, ou pelo menos a tentativa de compreensão da natureza é a teoria quântica. E o que propõe? Que o espaço, daquela maneira que nós conhecíamos, não é mais o mesmo, porque as coisas não podem ocupar o mesmo espaço. E como você explica isso? Assim: você mora em...?

\section{Em Berlim.}

E você?

\section{Em Frankfurt.}

Mas você trabalha em...?

\section{Em Gießen.}

E quantos habitantes tem em Gießen?

\section{Oitenta mil.}

E quantos tem aqui? 


\section{Setecentos mil.}

Quando você pega um metrô aqui, por exemplo, o espaço que você ocupa é diferente do espaço que você ocupa em Gießen ou em Berlim. Se você, por exemplo, pega um avião em Frankfurt e vai para São Paulo, você vai ocupar um espaço diferente. Se você pega um metrô em São Paulo, vai ocupar um espaço também completamente diferente. Quando estou no interior do Brasil, o tempo é diferente de quando eu estou em São Paulo. Por exemplo, de manhã quando acordo em minha cidade, Cataguases, que é pequenininha, e vou ao banco, ao supermercado, converso com os amigos, são 10 horas da manhã, e em São Paulo, 4 horas da tarde, porque a mesma coisa que eu faria nesse tempo lá eu demoraria muito mais. Portanto, essa noção de espaço e tempo não é a mesma noção do século XIX, e eu tento usar essas estratégias narrativas dentro do romance. E é por isso que eu chamo as minhas obras de romance.

Há críticos literários que consideram que a obra de Ana Paula Maia, com que também falei, forma parte do neonaturalismo ou neorrealismo. Você acabou de estabelecer uma conexão entre a física, como explicação da natureza, e o romance, como explicação da natureza humana. Você se considera também um autor neonaturalista?

Não. O naturalismo tenta compreender a natureza humana a partir de pressupostos da biologia e eu tento estabelecer uma relação com a física. E é diferente, pois não é determinista. O naturalismo é determinista, e mesmo o neonaturalismo é determinista. E a física não é determinista, ela é exatamente o oposto.

\section{A física clássica também é determinista.}

A física clássica do Newton, sim, mas já a de Einstein, não. A física quântica é um passo além de Einstein, por isso eu não me considero naturalista. Eu não assumo esse rótulo porque o que eu persigo é a diluição desse determinismo, mostrando justamente o contrário: se você está aqui, está ali, está lá, é por razões que estão muito além da questão biológica e que não têm nada a ver com a mesma. Têm a ver com a questão física. 
A sua literatura gira muito em torno dos proletários, dos operários da metalúrgica, entre outros. Por que você se interessa particularmente por essa classe social?

Em primeiro lugar porque eu fui operário têxtil, eu fui torneiro mecânico. Minha mãe era analfabeta, lavadeira de roupas e meu pai era semianalfabeto e pipoqueiro. Eu trabalho desde os seis anos de idade em tudo o que você puder imaginar. Só não fiz coisa errada, mas as coisas certas eu fiz todas. Eu fui operário têxtil, fui torneiro mecânico, jornalista... Meu interesse por esse universo deu-se primeiro porque eu conheço muito bem esse universo, meus amigos são desse universo, meus pais são desse universo, os pais dos meus amigos são desse universo. Mas isso apenas não daria uma explicação para mim. A minha explicação segunda é: quando eu comecei a ler literatura brasileira eu descobri que a literatura brasileira não trata desse assunto. Então fiz uma decisão política - e também estética: eu resolvi escrever sobre esse assunto e preencher essa lacuna. Evidentemente eu não quero dizer com isso que se faça literatura boa ou não, não vou discutir isso, mas é olhar para esse universo.

Para essas personagens a violência é um tema constante, elas sofrem vários tipos de violência: a violência física às vezes muito crua, a violência doméstica, a violência laboral e econômica muito agudas. Contudo, há vários escritores brasileiros que falam de diferentes tipos de violência, por exemplo, o Marcelino Freire, o Ferréz, a Patrícia Melo. Qual a diferença entre a sua literatura e a literatura deles?

Eu diria que é uma diferença bastante grande, que se dá da seguinte forma: com os personagens da Patrícia Melo a violência se dá a partir de um enfrentamento policial. Na literatura do Ferréz se encontra a violência da periferia da cidade, das pessoas marginalizadas. Também assim ocorre na literatura do Marcelino, de forma mais estilizada. No meu caso a grande diferença é que meus personagens não estão num mundo contra a sociedade, mas, sim, em um mundo para pertencer a ela. E o fato de eles quererem pertencer à sociedade é o que gera a violência. Os personagens da Patrícia estão contra a sociedade e a sociedade está contra eles, e na minha literatura, não. Para mim é uma diferença sutil mas determinante. Meus personagens querem comprar uma televisão, um carro bacana, eles querem comer bem. Eles não querem traficar droga, eles só querem participar daquilo que a 
sociedade tem de melhor. Eles só querem ter uma ascensão social, e isso gera violência. Certa feita alguém me perguntou assim: "Você faz realismo-socialista?", e eu respondi: "Não eu faço realismo-capitalista".

Os seus personagens não têm vocação de revolucionários.

Não, muito pelo contrário. Os personagens não querem combater a sociedade capitalista, eles querem pertencer à sociedade capitalista. O grande problema deles é exatamente esse: não fazer parte dessa grande festa que é o Brasil. Eles estão sempre à margem, não no sentido de "marginal", mas no sentido de que eles não foram incorporados à sociedade. São apenas uma parte da engrenagem que produz riqueza mas não usufrui dela.

Isso é um tipo de marginalização diferente da marginalização da Zona Sul de São Paulo, por exemplo.

Exatamente. Tanto que em geral entre meus personagens não tem bandidos nem traficantes de drogas. Se tem, são ocasionais. São personagens totalmente dentro da sociedade, só que estando apenas no limiar.

Gente de bem...

Gente de bem, mas que são violentíssimos com as mulheres, com as crianças, e entre eles mesmos. Eles são bons e maus, fazem qualquer coisa para subir na vida. Eles estão, digamos, dentro de um registro psicológico de querer pertencer a algum lugar e não pertencer.

Eles eram muitos cavalos é um romance de um dia em São Paulo, mas, em geral, em sua obra muitos dos seus personagens são de Minas Gerais. A sua literatura é uma continuação do Regionalismo do século XX. Eu me refiro a obras como Vidas secas, do Graciliano Ramos. A crueldade das pessoas de Vidas secas parece-se com a crueldade dos personagens nas suas obras.

Eu compreendo a sua pergunta, acho que você não está equivocada, mas eu vou fazer só um pequeno adendo, veja bem. Todas as vezes que você adjetiva a literatura, é uma maneira de diminuir a importância dela; vou te dar um exemplo: quando você fala, por exemplo "O autor 
fulano de tal é um autor de literatura gay", você está tirando dele o fato de ele ser autor de literatura.

É um gueto. É um gueto literário.

Quando você fala também: "essa é uma literatura negra", você está colocando o autor em um escaninho e dizendo "eu faço literatura, mas ele faz literatura negra, eu faço literatura, mas ele faz literatura gay, eu faço literatura, mas ela faz literatura feminina, eu faço literatura, mas ele faz literatura marginal, eu faço literatura, mas ele faz literatura regionalista". Eu embora compreenda a sua colocação, eu não assumo isso, porque é uma maneira de desqualificar, porque quando você qualifica, você está desqualificando.

É um desejo dos acadêmicos o de querer sempre qualificar, não é?

Eu poderia falar assim "eu faço literatura proletária”. Mas não, eu faço "literatura". O meu universo é esse, o meu universo é proletário, é Minas Gerais. Mas eu não faço literatura mineira, nem literatura proletária. O que eu faço é literatura. Ou pelo menos quero... não sei se eu consigo, mas eu não aceito adjetivos.

O livro De mim já nem se lembra é a edição de cartas do seu irmão. Qual a relação entre ficção e realidade nesse caso?

A começar pelo fato de que essas cartas não existem.

O narrador, Luiz Ruffato, começa o livro afirmando que essas cartas existem, e eu acreditei...

Não só isso, mas nas cartas o irmão chama ele de Luizinho, que é o Luiz Ruffato. E não só isso, eu tive um irmão chamado José Célio. E minha mãe, que se chama Geni, está lá. E minha irmã, que se chama Lúcia, está lá. A minha filha, que se chama Helena, está lá. Tudo aquilo - os nomes - é verdade, menos as cartas. Quando eu falo com minha irmã a respeito da minha mãe, ela fala assim "Não, mas pera aí, não é a mesma mãe que eu tive". E não é mesmo, porque a mãe que eu tive é minha mãe e a mãe dela é a mesma e não é a mesma. Então, se meu irmão tivesse escrito 
cartas, ele teria escrito aquelas cartas. Como ele não escreveu, eu escrevi para ele e, portanto, para mim elas passam a existir.

E sua mãe não era analfabeta?

Analfabeta...

E não escrevia cartas?

... e nem lia cartas.

É realmente interessante porque eu achava que só era um trabalho redacional, estilístico, uma adaptação das cartas reais.

Todo mundo acha isso. E quando eu digo que não as pessoas ficam decepcionadas: "Como assim, você me enganou!". Como assim eu enganei... é a vida quem engana a gente.

E não é mentira, é ficção. Tem uma diferença muito importante.

Falando ainda um pouco sobre a violência doméstica no Brasil. Você diria que em certas classes sociais a violência já é uma forma de resolver qualquer tipo de conflito, como os ciúmes? Se há ciúmes na relação o único modo de resolver isso acaba sendo a violência. Em que medida se mantém ainda o valor da fidelidade, da confiança, como base da família?

Eu acho que a violência acaba sendo uma válvula de escape, no sentido de que é tudo tão ruim, a vida é ruim, eles moram mal, vivem mal, com salários ruins, morando longe, a polícia é corrupta, há o narcotráfico. Isso é tudo tão ruim que isso acaba fazendo com que você tenha uma relação com a vida ruim também. E não são só as mulheres que apanham. As crianças também apanham. Então, eu, que sou o porteiro do edifício e passo o dia inteiro sendo humilhado, porque as pessoas não me veem e quando me veem me tratam mal, o que eu faço? Eu vou aproveitar de quem é mais fraco que eu. Ou da minha mulher ou do meu filho. Tem uma filosofia em Estive em Lisboa e lembrei de você. Lá há um personagem, o Serginho, que diz assim: "Quem tem um carro bom passa por cima de quem tem um carro ruim, quem tem um carro ruim passa por cima de quem uma motocicleta, quem tem uma motocicleta, passa por cima de quem tem uma bicicleta, e quem tem uma bicicleta 
passa por cima de quem não tem nada, e essas pessoas que não tem nada passam por cima daquelas pessoas que, por exemplo, são aleijadas et cetera e tal". Lembra aquela historinha do peixe grande com o peixe pequeno...? É aquilo. O Brasil é uma imagem muito boa.

Você diria que a violência é também uma forma de se comunicar quando a comunicação verbal falha?

Eu acho isso perigoso, porque é como se justificasse essa estratégia. Eu acho injustificável. É o exercício do poder. É uma criança maior batendo numa menor. É um homem batendo numa criança. É um homem batendo numa mulher. É uma mulher batendo numa criança. Porque as mulheres também não se salvam disso; as mulheres também são muito violentas com os filhos. Então essa é uma questão de poder, eu acho, não é uma questão de comunicação.

O Brasil está se preparando para a Copa do Mundo. Eles instalaram unidades da UPP nas favelas e houve muitas manifestações, sobretudo de pessoas da classe média. Você acha que tudo isso vai levar a alguma melhoria? Como isso continuará depois da Copa do Mundo?

Pois é, essa é uma questão que eu não sei. É complexa. Esses movimentos se iniciaram a partir de uma reivindicação muito concreta, que era a redução do preço das passagens dos ônibus urbanos. Quando houve uma violência policial imensa para reprimir essas passeatas, todas as pessoas de bem se indignaram e foram para a rua. E daí vieram aquelas passeatas imensas. Mas depois da segunda vez que as passeatas imensas foram paras as ruas, as pessoas começaram a perguntar o porquê de elas estarem indo para lá. E aí elas perceberam que não estavam indo para as ruas pelos mesmos motivos: eu, você e o Christian estávamos indo para as ruas por motivos diversos. E, já que eu não tenho o mesmo motivo para ir para a rua que você e o Christian, essas passeatas foram esvaziadas e passaram a ser passeatas pequenas, nas quais grupos - não se pode discutir se eram legítimos ou não, não importa - continuaram atuando. Agora, voltaram algumas passeatas um pouco maiores com reivindicações muito específicas de novo, como na educação. A educação é sem dúvida um assunto que indigna toda a população brasileira, assim como a saúde, assim como a corrupção. A dúvida é: nós vamos ver daqui para a frente as pessoas irem às ruas 
com reivindicações concretas, como educação, saúde, corrupção, ou vão continuar sendo reivindicações pequenas, pontuais. Nesse último caso provavelmente não vai acontecer muita coisa. Eu não sei.

E a Polícia Pacificadora, acha que tem algum sentido ou é só para criar certa imagem no exterior?

Eu gosto de me perguntar o contrário: se era tão simples assim, por que não foi feito antes? Que a presença do Estado nas favelas nunca existiu e era importante é verdade. Mas por que só agora isso acontece? Não tenham dúvidas de que é por causa da Copa do Mundo. Agora, o que a maioria das pessoas não sabe é que as Unidades Pacificadoras existem na Zona Sul do Rio de Janeiro, que é o cartão-postal e única coisa que será vista no ano que vem pelos europeus, pelos americanos e outras pessoas. Ninguém sabe o que está acontecendo na Zona Oeste ou na Zona Norte do Rio de Janeiro, ninguém sabe. Não existem Unidades Pacificadoras nesses lugares. Portanto, para mim, mais uma vez, isso é pintar uma casa que está caindo aos pedaços. Você não quer arrumar a casa...

\section{É cosmética...}

Isso é cosmética. É importante? Não tenho dúvida de que é importante, não estou dizendo que não é importante; estou dizendo apenas que não resolve o problema. É importante que o Estado esteja presente nesses lugares? Sem dúvida. Mas isso só vai se resolver no dia em que tivermos distribuição de renda no Brasil, a qual não temos, quando tivermos educação no Brasil, a qual não temos, quando tivermos saúde no Brasil, a qual não temos, quando prendermos os corruptos do Brasil, e nós não prendemos. 